\title{
Archaeological Park and Cultural Centre at the El-Zuma Cemetery: A Future Concept
}

\author{
Mahmoud El-Tayeb
}

At the beginning of the first season of excavation, in December 2004, some leading figures of the local community expressed their gratitude for our work and their happiness that, at last, the cemetery area will be free of obstacles. Obviously, this meant that they needed the land for housing projects. Nonetheless, the results of the excavation of the first tumulus, T.2, with its rare type of Ushaped ground plan and an underground tunnel, seemed to encourage the same gentlemen to ask if this burial could be left open for visitors. Since the cemetery field is situated in the middle of the village and it is the favourite place for local children to come and play, the natural answer was a definite 'no.' However, an alternative solution was reached, which resulted in the substructure of the burial being covered with a metal grid fitted with a door allowing easy access to the bottom of the grave. As a matter of fact, the idea of the Archaeological Park was born in consequence of the active engagement of the whole local community in El-Zuma.

Generally speaking, the idea is quite simple. The unique types of burials at this site should be reconstructed and exhibited as an open-air museum or an archaeological park. The disturbed superstructures of T.2 and T.5 should be restored to their original shape. Both of these type I tombs have tunnels and were fully excavated during the first two seasons. They were subsequently covered with metal grilles, installed in cooperation with the local community, as a temporary protection measure. Two tombs of type II, with flattened tops, T.25 and T.12, were also protected in the same manner as the type I burials. The proposed tomb reconstructions must not disrupt the panorama of the whole cemetery field, thus fulfilling the conditions set out by the National Corporation for Antiquities and Museums as well as the UNEsco guidelines.

In all the aforementioned graves, copies of the finds that were excavated from them would be displayed inside the burial chambers, in their original locations, to give the visitor an idea of the burial customs of the period. The next plans concern the tunnels in T.2, T.5, T.6, and T.7. The last tumuli, T.6 and T.7, are the largest and the highest in the field; yet only their external shafts and tunnels were excavated. In both cases, the tunnels are of unique, monumental construction, and hence deserve to be open to visitors, tourists, scholars, and students of archaeology alike. The tunnels still require conservation and consolidation work, and for safety reasons access would be allowed only to their external shafts.

The last aim of the project is to create a Cultural Centre consisting of a small gallery with audio-visual displays, a meeting hall, an open theatre, offices, and guest rooms, in addition to a tourist police station, and a public family park (garden) with refreshment facilities. The centre would also have a visitor car park.

The ultimate goal is not just to share the results of the El-Zuma excavations and raise awareness among the Sudanese about an important chapter of their history. It is hoped that the Cultural Centre will also help to revive the local rural community, both socially, by providing a platform for integration between the different ethnic groups that live in the area (mainly the Shayggyia, Hawawir, and Hassanyia), and economically, by creating jobs in various service and commercial sectors. This would be especially beneficial for young people, as it would help them to improve their standard of living, and consequently encourage them to stay in their hometown instead of migrating towards the big cities to work as cheap labour (even if they are university graduates). The revival of traditional local crafts could also be of significance for the older generation. Other activities that could be organized at El-Zuma include short trips on camels and donkeys (which the mission has already successfully trialled), camel-racing festivals run by groups from the Hawawir and Hassanyia, and artistic performances given by the Shayggyia singers.

This proposal was included in PCMA's first application to the Qatar-Sudan Archaeological Project in 20o9, but there was no chance to implement it without preparing an engineering design and a separate budget for it. Bashmuhandis Abdallah Sabbar subsequently created designs for the reconstruction of the aforementioned tombs and for the construction of the Cultural Centre. A second method for reconstructing the tombs was designed by Engineer Jolanta Juchniewicz (see Chapter 5, this volume). 
Finally, it is fair to say that the realization of such a comprehensive project would play an important role in promoting tourism in this central zone of the Dongola Reach, with its rich monumental complexes at Jebel Barkal, Nuri, and El-Kurru, as well as downstream at other unique sites, such as Selib, Banganarti, Old Dongola, and Kerma. 